\title{
Interação família-escola no desenvolvimento do aluno surdo
}

\author{
Family-school student interaction on the development of deaf
}

\author{
Wender Faleiro* \\ Magno Nunes Farias ${ }^{* *}$ \\ Lázara Cristina da Silva**
}

\section{Resumo}

Diversos desafios permeiam o processo educacional do surdo, principalmente questões que envolvem a linguagem, as relações familiares e escolares. Assim, o objetivo deste estudo é analisar como ocorre a relação da família dos surdos com a escola. Trata-se de um estudo qualitativo, com coleta de dados por meio de questionários respondidos por professores de escolas públicas de diversas partes do Brasil. Foram evidenciadas nos discursos grandes problemáticas dentro da integração família-escola nos ambientes escolares, e os fatores mais apontados foram: a organização do ambiente educacional e a dificuldade de responsabilização e instrução dos familiares. Para melhorar a relação família-escola, os professores sugerem a disponibilização de espaços de integração, que vão além da reunião, como cursos de formação e participação em apresentações, rodas de conversa, e o oferecimento de curso de Libras aos familiares, pois a grande maioria dos familiares apresenta resistência a essa língua e não realiza uma comunicação efetiva e completa com os surdos. A integração família-escola contribui para o desenvolvimento escolar do sujeito surdo, pois essa rede formada consolida-se pelas relações e interações das pessoas e pode auxiliar a lidar com questões de âmbito afetivo e emocional.

Palavras-chave: Educação a distância. Formação continuada. Relação Família-Escola. Surdez.

\section{Abstract}

Several challenges permeate the education of the deaf process, particularly issues involving language, family and school relationships. The objective of this study is to analyze how does the family relationship of the deaf with the school. Treat yourself to a qualitative study with data collection questionnaires answered by public school teachers from different parts of Brazil. It showed the great speeches problem within the family, school integration in school environments, and the most mentioned factors were: the organization of the educational environment; the difficulty of accountability and education of family members. To improve family-school relationship, teachers suggest the availability of integration spaces that go beyond the meeting, such as training courses and participation in presentations, conversation circles, and offering ongoing pounds to the families, because most the family has resistance to this language, and do not realize an effective and complete communication with the deaf. Integrating family-school contributes to the academic development of the deaf subject, as this formed network will consolidate the relations and interactions of people, and can help deal with affective and emotional level issues.

Keywords: Continuing education. Deafness. Distance education. Family-school relationship.

Recebido em: 09/09/2016 - Aprovado em: 14/06/2017

http://dx.doi.org/10.5335/rep.v24i3.7768

Doutor em Educação na área de Práticas e Saberes pela Universidade Federal de Uberlândia. Docente do Programa de Pós-Graduação da Faculdade de Educação da Universidade Federal de Goiás, Regional Catalão. E-mail: wender. faleiro@gmail.com

** Mestrando do Programa de Pós-Graduação em Educação da Universidade Federal de Goiás, Regional Catalão. Membro do Grupo de Estudos, Pesquisa e Extensão em Ensino de Ciências e Formação de Professores (Gepeec). E-mail: magnonfarias@hotmail.com

*** Doutora em Educação pela Universidade Federal de Uberlândia. Docente do Programa de Pós-Graduação em Educação na mesma instituição. Membro do Grupo de Estudos e Pesquisa Políticas e Práticas em Educação Especial e Inclusão Educacional (Gepepes). E-mail: lazara_cristina@hotmail.com 


\section{Introdução}

A família e a escola são duas instituições que dividem atribuições sociais, políticas e educacionais na vida das pessoas, tendo em vista que são espaços que influenciam e cooperam na formação da sociedade, ou seja, são instituições que se organizam e fornecem conhecimentos que estruturam e modificam os caminhos sociais de acordo com as particularidades de cada contexto. É importante destacar que esse potencial de transformar os sujeitos e grupos sociais pode ocorrer de maneira positiva ou negativa nos processos evolutivos e de desenvolvimento cultural, físico, social, intelectual e emocional de determinados sujeitos ou coletivos (DESSEN; POLONIA, 2007; MARTINS; TAVARES, 2010).

Na sociedade contemporânea, família e escola são dois contextos de promoção de desenvolvimento, socialização e educação da criança, que se definem e são diferenciados por padrões de comportamento, de objetivos, de procedimentos para transmissão de informações que lhes competem (PEREZ, 2008, p. 12).

De acordo com Perez (2008), o processo educativo é dividido em socialização primária e socialização secundária. Socialização primária diz respeito ao movimento social que ocorre em âmbito familiar, são os contatos iniciais que a pessoa possui na infância, pelos quais se torna membro da sociedade e incorpora aspectos culturais, normativos, morais, afetivos e sociais. Socialização secundária se dá por meio da escola, pois é um ambiente em que a pessoa é introduzida já socializada, porém interage com novos grupos e setores da sociedade. É o lugar onde se estabelece o conhecimento formal, mas também se estimula criação e legitimação de habilidades sociais em âmbito cultural e moral.

A família tem um papel fundamental na vida de seus filhos; por ser o primeiro ambiente de socialização, tem uma forte influência no comportamento: nela se aprende formas de existir, pensar, ver o mundo e resolver problemas, ou seja, é o lugar em que se constrói repertórios de vida. Pode-se denominar como a matriz da aprendizagem humana, pois nesse ambiente o sujeito aprende a lidar e resolver conflitos sociais, a controlar suas próprias emoções, a expressar seus desejos e sentimentos, ou seja, a lidar com a diversidade de acontecimentos positivos ou negativos da vida, que se estabelecem a partir das relações com outras pessoas (DESSEN; POLONIA, 2007). E essas relações têm influências diretas nas relações estabelecidas em outros ambientes, principalmente na escola, que é espaço social secundário comum a todas as pessoas.

A escola é uma instituição social que reflete as transformações da sociedade e tem como função social auxiliar os seres humanos a vivenciar um mundo globalizado. Por meio de conhecimento organizado ou formal e atividades sistemáticas, 
esse espaço possibilita aos alunos apropriar-se de novas experiências e formas de viver, pensar e interagir; com o objetivo de desenvolver aprendizagem e funções psicológicas dos estudantes (cognitivas, morais, de personalidade, físicas, afetivas), promove consciência cidadã e condições para que possam habitar o mercado de trabalho (DESSEN; POLONIA, 2007). A escola e a família podem exercer funções semelhantes em certa medida, porém produzem interações sociais opostas e estabelecem relações sociais por meio de recursos diferentes, pois os conhecimentos produzidos em cada espaço possuem valores sociais distintos, mas as interações estabelecidas em um espaço interferem nas relações do outro: interações limitadoras e negativas na família podem gerar desorganização nas interações escolares, ou vice-versa.

Os laços afetivos estabelecidos nesses dois espaços, quando consolidados, ampliam a forma de lidar com a vida das pessoas, refletindo em todas as relações sociais. É importante que se consolide uma rede de relações e apoio entre esses contextos, para que os sujeitos inseridos em ambos possam transitar entre eles e apoiar-se para a construção de repertórios para lidar com os desafios singulares da vida (DESSEN; POLONIA, 2007). Segundo Hollerweger e Catarina (2014), a integração família e escola e a construção de uma rede de relações e apoio ao desenvolvimento do deficiente ou não são fundamentais, pois o trabalho escolar terá mais êxito se os familiares acompanharem diretamente esse processo e a pessoa se tornará mais segura para desenvolver suas habilidades tranquilamente, além de obter uma ponte de comunicação que pode oferecer recursos tanto para a escola quanto para a família sobre formas de superar desafios de aprendizagem que pode ocorrer.

Porém, evidencia-se que, apesar da importância da interação saudável desses dois espaços, ainda há barreiras que geram conflitos, dificultam a interação e produzem ruídos na comunicação. Para Dessen e Polonia (2007), essa dificuldade se dá pelo fato de os espaços acadêmicos e sociais de interação não possibilitarem $o$ compartilhamento de responsabilidades entre esses dois microssistemas.

Essa interação, quando diz respeito à família de pessoas com deficiência, atravessa outras particularidades; essa família passa por inúmeros sentimentos, como lamentação, autopiedade, decepção e culpa, por não ter o filho "esperado", além do medo do futuro, do receio de conseguir uma escola adequada, dentre outras dificuldades. A sociedade tende a pensar que pais de filhos com deficiência apresentam maior potencial para lidar com a situação, porém todos estão em processo de aprendizagem, e a parceria com a escola também pode contribuir para superação desses obstáculos. É fundamental que, no processo de inclusão, essa parceria seja fortalecida tanto para potencializar o processo educacional quanto para auxiliar as famílias a lidar com experiências novas. Deve ser construída uma ponte de ajuda 
mútua para o enfrentamento de possíveis barreiras sociais para o desenvolvimento da pessoa com deficiência (HOLLERWEGER; CATARINA, 2014).

Após evidenciar a importância desses dois espaços no desenvolvimento humano, o objetivo é analisar como esses processos acontecem dentro das particularidades educacionais do surdo, entendendo que a integração entre a família e a escola é essencial para o desenvolvimento saudável de qualquer ser humano. Porém, as pessoas com deficiência primária; são questões que envolvem desinformação, preconceito e estigmas historicamente construídos e legitimados por uma sociedade que tende a excluir pessoas com o desenvolvimento atípico (MARTINS; TAVARES, 2010; HOLLERWEGER; CATARINA, 2014).

A escola, por muito tempo, legitimou o processo de educação excludente, no qual a escolarização era vista como um privilégio de alguns grupos, sem qualquer política educacional eficiente para a particularidade das pessoas com deficiência. Porém, principalmente a partir da década de 1990, começa uma nova forma de se pensar a inclusão escolar, em que todos os brasileiros, independentemente de apresentar desenvolvimento típico ou atípico, têm o direito de acesso à escola e de permanência nela (LACERDA, 2006; HOLLERWEGER; CATARINA, 2014). Ocorre, então, uma reestruturação escolar, para possibilitar o acesso às oportunidades oferecidas pela escola por todos.

A escola inclusiva pressupõe que todas as crianças possam aprender e fazer parte da vida escolar e social. Há a valorização à diversidade, a crença de que as diferenças fortalecem a todos os envolvidos. O movimento mundial pela educação inclusiva é uma ação política, cultural, social e pedagógica, em defesa do direito de todos os alunos de estarem juntos, aprendendo e participando, sem nenhum tipo de discriminação (HOLLERWEGER; CATARINA, 2014, p. 4).

Sendo assim, o sujeito surdo apresenta total direto, como cidadão, de ter acesso à escola, tendo em vista as práticas educativas inclusivas. Porém, a educação da pessoa surda ainda é um grande desafio no que diz respeito à inclusão escolar. Segundo Lacerda (2006), no Brasil e no exterior, os dados indicam que pessoas surdas que passaram pela escolarização mostram um rendimento muito inferior, pois apresentam pouca competência para aspectos acadêmicos, quando comparadas a alunos ouvintes.

A linguagem é a principal estrutura responsável pela regulação dos processos psíquicos, pois, por meio dela, se organizam e se estruturam as funções cognitivas, possibilitando interações fundamentais para composição do conhecimento. Ela é adquirida a partir da interação com outras pessoas, tendo o contato direto com a linguagem e utilizando-a, sendo uma função fundamental para diferenciar o ser humano de outros animais. As pessoas surdas podem ser prejudicadas diante des- 
se processo, pois vivem com um déficit auditivo que as impossibilita de adquirir naturalmente a língua oral/auditiva, utilizada pela comunidade majoritária, o que acaba por dificultar a inserção cultural, podendo comprometer o desenvolvimento cognitivo, social ou emocional (VIGOTSKI, 2001; LACERDA, 2006; KELMAN et al., 2011). Devido às dificuldades desenvolvidas pelas questões da linguagem, o sujeito pode ter um desempenho escolar aquém do esperado.

A partir de uma perspectiva histórico-cultural, a dificuldade de se desenvolver a fala (palavra) é o que gera os principais problemas do desenvolvimento do surdo. De acordo com essa teoria, o signo é o instrumento fundamental para o desenvolvimento das funções psicológicas superiores, por isso o surdo fica defasado nesse aspecto, pois geralmente suas interações sociais são com ouvintes, ou seja, com sujeitos que não partilham de um mesmo sistema comunicacional que a pessoa surda. Com a família se constituem as primeiras relações, que envolvem a esfera social e simbólica por meio do convívio, porém, o surdo não possui essa estrutura, visto que, muitas vezes, sua família se constitui por pessoas ouvintes, gerando um movimento de interação pobre entre os sujeitos, que não proporciona o poder de realizar recorte dos significados das suas vivências no mundo (LACERDA, 2006; VIGOTSKI, 1989).

Para superar a barreira da língua oral, a língua de sinais é o que possibilita ao surdo desenvolver suas funções cognitivas. O processo de desenvolvimento do surdo ocorre de maneira igual ao do ouvinte, por meio das interações sociais e com a aquisição das significações das suas vivências durante o encontro com o mundo externo, a única diferença é que ele possui a necessidade de um canal linguístico em comum com o outro sujeito com o qual está compartilhando a vivência, ou seja, ambos devem usar a língua de sinais. Estudos apontam que a interação de uma pessoa surda com um adulto ou sujeito mais velho (adulto surdo ou ouvinte sinalizante fluente) que utilize a língua de sinais é fundamental para seu desenvolvimento e para organização do pensamento concreto e abstrato; é importante também que esse adulto seja um sujeito da família, para que mantenham estreita relação (ALMEIDA, 2009).

Evidencia-se, então, que a língua de sinais é um fator decisivo para uma efetiva inclusão escolar (ALMEIDA, 2009; KELMAN et al., 2011). Isso caracteriza um desafio nesse processo, pois, na maioria dos casos, os membros da família de surdos são ouvintes, não utilizam a língua de sinais como forma de comunicação. Estudos apontam que há uma diminuição de interação entre pais ouvintes e filhos surdos, além de existir resistência familiar em aceitar a língua de sinais como forma de comunicação. 
No Brasil, surge a língua de sinais em âmbito nacional, denominada Língua Brasileira de Sinais (Libras), que é reconhecida pela Lei Federal no 10.436, de 24 de abril de 2002. Essa lei legitima que o poder público deve difundir e apoiar seu uso em todos os serviços públicos, com o objetivo de superar as barreiras linguístico-discursivas que os sujeitos surdos enfrentam (SCHEMBERG; GUARINELLO; MASSI, 2012).

Podemos observar diversos desafios que permeiam o processo educacional do surdo, principalmente questões que envolvem a linguagem, as relações familiares e escolares e a interação entre elas. Então, o objetivo deste estudo é analisar como ocorre essa relação da família dos surdos com a escola, bem como essas relações diante das singularidades de vivências do sujeito surdo, podendo assim contribuir para a discussão sobre os desafios da escolarização dos surdos. Acredita-se que tanto a família quanto a escola possuem papéis fundamentais no processo educacional desse aluno, sendo fundamental entender como essa relação ocorre e de que forma ela pode ser positiva ou negativa nesse processo.

\section{Metodologia}

Trata-se de um estudo qualitativo, devido ao fato de ser esta uma abordagem com o potencial de capturar e compreender o significado que os indivíduos ou grupos atribuem a uma questão humana ou social (CRESWELL, 2010). Além disso:

A palavra qualitativa implica uma ênfase sobre as qualidades das entidades e sobre os processos e os significados que não são examinados ou medidos experimentalmente (se é que são medidos de alguma forma), em termos de quantidade, volume, intensidade ou frequência (DENZIN; LINCOLN, 2006, p. 23).

A pesquisa qualitativa surge a partir da necessidade de se entender sujeitos e grupos sociais em suas relações com o mundo externo. Ela possibilita aprofundar a subjetividade de sujeitos ou coletivos, a fim de explorar os fenômenos estudados com maior intensidade e com uma carga mais ampla de questões subjetivas (DENZIN; LINCOLN, 2006).

Os sujeitos da pesquisa foram professores da rede pública de ensino de diversas regiões do Brasil, que participaram do curso de extensão em "Aperfeiçoamento em Atendimento Educacional Especializado para alunos surdos. Na modalidade a distância, na IX turma, que ocorreu no primeiro semestre de 2015. Foram oferecidas 50 turmas com 20 vagas cada, totalizando mil vagas, contudo, foram matriculados 1.038 participantes; devido à grande procura e já prevendo futuras evasões, ultrapassou-se um pouco o número de matriculados. Esse curso é oferecido desde 2007 pela Universidade Federal de Uberlândia (UFU), sob a coordenação do Centro 
de Ensino, Pesquisa, Extensão e Atendimento em Educação Especial (Cepae), em parceria com o Ministério da Educação (MEC), por meio da Secretaria de Educação Educação Continuada, Alfabetização, Diversidade e Inclusão (Secadi).

Para a coleta de dados, foram utilizadas duas perguntas do questionário on-line que os professores responderam antes do início do curso. O questionário inicial era do tipo misto, ou seja, composto por questões abertas e fechadas. Eram 35 questões com o objetivo de identificar o perfil acadêmico e captar experiências dos docentes e perspectivas sobre o curso. Para responder aos objetivos do presente estudo, foram selecionadas as questões relacionadas à interação família-escola no contexto educacional dos alunos surdos. Do questionário inicial, foram analisadas duas questões abertas: 1) qual a relação das famílias dos alunos surdos com a escola?; 2) como é a aceitação da Libras por parte da família dos alunos surdos?

\section{Resultados e discussão}

De todos os profissionais matriculados, apenas $562(54,1 \%)$ responderam efetivamente ao questionário. $\mathrm{E}$, na análise das respostas, verificou-se que a maioria relatou percepções e experiências das vivências sobre a relação família, escola e surdo e sobre questões que envolvem essa dinâmica. Quando questionados sobre qual seria a relação estabelecida entre família e escola, surgiram diversos tipos de discursos. A seguir, são analisados os mais relevantes:

Precária, pois as famílias não aceitam a surdez (Docente A).

Não muito próximas, procuramos aproximá-los, mas a correria do dia a dia da família e do cotidiano escolar não nos permite ser mais próximos (Docente B).

A partir desses discursos, pode-se evidenciar que há grandes problemáticas dentro da integração família-escola em alguns ambientes escolares em que os docentes atuam. Na fala do docente $\mathrm{A}$, é apontada a não aceitação da surdez como ponto principal para a precária relação da família com a escola. Diante disso, é importante destacar que essa problemática não reside na deficiência da pessoa, mas, sim, nas pessoas que estão dentro de uma perspectiva social estreitamente relacionada com o preconceito e a dificuldade de aceitação da diversidade humana. Inicialmente, a aceitação da família perpassa grandes dificuldades, pois muitos ficam se questionando a todo o momento o porquê desse acontecimento, mas, uma vez que a informação é fornecida e ocorre tomada de consciência sobre a deficiência do filho, o processo de aceitação tende a acontecer, e isso possibilita a abertura para essa família entender e contribuir para o desenvolvimento do ser humano, fazendo 
novas construções relacionais e pedagógicas, estabelecendo novas prioridades, ou seja, reorganizando-se e aprendendo a favorecer o desenvolvimento saudável da pessoa surda.

Enquanto o movimento de reconhecimento e valorização das pessoas surdas, de suas especificidades culturais, linguísticas, portanto identitárias, não ocorrer, fica pouco possível estabelecer uma rede de relação entre família e escola, pois a família não se abre para compreender as particularidades do surdo e seu papel junto da escola para o desenvolvimento desse sujeito, como para estabelecer meios de comunicação e interação com a pessoa surda, para ela vivenciar o mundo e desenvolver habilidades (NEGRELLI; MARCON, 2006). Sendo assim, é fundamental que a escola estabeleça um diálogo aberto com essa família, auxiliando-a a buscar profissionais e grupos para que possam trabalhar esse processo de aceitação.

Já, na fala do Docente B, nota-se o apontamento da existência de um arranjo organizacional no estabelecimento educacional que pode dificultar a construção de uma rede relacional entre escola e família. Isso já foi descrito por Dessen e Polonia (2007), que indicam que os espaços acadêmicos e, até mesmo, os sociais, em geral, tornam possível um compartilhamento de competências e responsabilidades entre família e escola. Além disso, há uma problemática geral no que diz respeito a recursos humanos e financeiros, capazes de tornar a escola um espaço com maior possibilidade de interagir com a comunidade.

Para superar as barreiras organizacionais e os paradigmas impostos na divisão de responsabilidade descritos anteriormente, Carneiro (2003) destaca a necessidade de desconstruir culturalmente a ideia da escola como instituição fechada e com o poder centrado em seus próprios integrantes (professores, coordenadores, entre outros), para criar uma instituição que possa abrir as portas, tornando-se um espaço para comunidades, com novos projetos político-pedagógicos para desenvolver um novo tipo de interação. Deve-se também utilizar acontecimentos do contexto da família no processo de aprendizagem, valorizando e utilizando os recursos educativos familiares para favorecer o desenvolvimento acadêmico do sujeito (DESSEN; POLONIA, 2007).

A seguir, destacam-se outros recortes de respostas dos professores:

Na maioria dos casos a família é ausente e só comparece após vários pedidos de seu comparecimento. Geralmente as famílias delegam obrigações (Docente C).

Muitas vezes as famílias depositam somente na escola a responsabilidade de esse aluno aprender, o que sabemos que o que deve acontecer é a união entre escola e família (Docente D).

Nas falas dos Docentes C e D, verifica-se a dificuldade de responsabilização dos familiares como uma barreira para uma comunicação mais efetiva e sem de- 
sentendimentos. Essa questão pode estar envolvida com diversos fatores, como a dificuldade em aceitar as particularidades do filho e em compreender a necessidade do filho de ter um maior apoio para o seu desenvolvimento, assim como achar, realmente, que a escola é a única responsável pelo processo educacional. De acordo com Hollerweger e Catarina, a interação família-escola assume funções para o desenvolvimento do sujeito surdo, que podem ser descritas em:

[...] demonstração de amizade, passando confiança e coragem para a criança; pais cooperantes no processo de ensino-aprendizagem; tomada de conhecimento dos pais sobre o desenvolvimento da criança; e obtenção de informações do ambiente da casa e da rotina diária da criança $(2014$, p. 11).

Sendo assim, é crucial para o processo educacional que a escola acione estratégias para promover ao máximo a oportunidade de convívio das famílias dentro da escola e, com isso, demonstrar que essa aproximação é positiva para potencializar o desenvolvimento do sujeito, dando início à conscientização dos familiares, para que se posicionem como agentes no acesso ao desenvolvimento (PEREZ, 2008; KELMAN et al., 2011; HOLLERWEGER; CATARINA, 2014). Esse processo é difícil e frágil, pois exige uma construção de vínculo entre a escola e os familiares, é importante levar essas discussões para as reuniões, mas também ir além, como construir espaços que não sejam somente para reuniões formais, mas, inclusive, para compartilhamentos de experiências, medos, angústias, construindo uma rede aberta de comunicação para ajudar no resgate dessa família, ou seja, locais para discutir emoções, afetos, estratégias, concepções, saberes e necessidades que rodeiam esses sujeitos. Além disso, podem ser elaboradas rodas de leitura e conversa sobre questões teóricas, para ampliar as informações (BARBA; MINATEL, 2013).

Muito presentes, mas com pouca instrução (Docente E).

É importante pensar, também, em espaços de caráter informativo, pois não basta a presença, como é relatado pelo Docente E, mas é importante que os pais estejam instruídos sobre as particularidades da surdez para que possam contribuir de maneira efetiva.

Dentro da mesma questão, algumas respostas apontaram interações positivas, dentre elas, destacamos as seguintes:

A relação das famílias dos alunos com a escola é ótima, os pais e familiares participam da formação de Libras e participam dos momentos de reuniões e apresentações (Docente F).

A família é bastante participativa, pois contribui para aquisição de conhecimentos do educando surdo (Docente G). 
$\mathrm{Na}$ escola em que atuo, a convivência é muito boa, conseguimos fazer diversas parcerias que, como resultado final, acabam por contribuir com o desenvolvimento do aluno (Docente $\mathrm{H}$ ).

Nota-se que a integração família-escola ocorre de forma positiva nos locais de trabalho desses sujeitos. Na fala do Docente G, observa-se a importância dos espaços de integração para isso acontecer, que vão além da reunião, como cursos de formação e participação em apresentações. Esse espaço coletivo (a escola) se torna, então, uma rede social de apoio para superar ruídos na comunicação, para ajudar todos os sujeitos a lidar com os desafios do desenvolvimento e da aprendizagem, favorecendo esse processo para o sujeito com deficiência.

Os Docentes G e H reafirmam o que os estudos apontam, a integração família-escola contribui para o desenvolvimento escolar do sujeito surdo, pois essa rede formada vai se consolidar pelas relações e interações das pessoas e pode auxiliar a lidar com questões de âmbito afetivo e emocional, uma vez que os sujeitos que integram esse grupo estarão vivenciando processos em comum, e isso pode fortalecer e empoderar esses sujeitos para enfrentar os desafios e para compartilhar as conquistas. Esse contato estreito pode dar à escola um novo repertório de maneiras de ensinar, utilizando as experiências que ocorrem em âmbito familiar para isso; assim, as estratégias podem ter mais sentidos positivos, e o envolvimento do aluno surdo será mais intenso. Esse espaço para compartilhar situações entre os sujeitos vai possibilitar trocas e aumentar as estratégias de aprendizado tanto no âmbito escolar quanto no familiar (DESSEN; POLONIA, 2007; BARBA; MINATEL, 2013).

Ao analisar a segunda pergunta, que versava sobre o uso da Libras por parte da família como aspecto primordial para o desenvolvimento escolar do sujeito surdo, evidenciou-se a resistência familiar ao uso dessa língua como forma de comunicação. As falas subsequentes indicam essa discussão:

Difícil, os pais não têm conhecimento da Libras assim como, não veem importância de o filho utilizá-la (Docente I).

A relação é um pouco complicada. A família da aluna que foi minha aluna, eles não conversam com a filha nem oralmente e nem com Libras. O pai não aceita Libras e acreditava que a filha após o implante coclear ouviria e falaria como uma pessoa não surda. Soube depois que isso não aconteceria. Presenciei várias cenas onde a aluna tentava conversar com a mãe e não era compreendida (Docente J).

A maioria das famílias não sabem Libras, mas a escola está oferecendo cursos para facilitar a comunicação das mesmas com os filhos [...] (Docente K).

Como já foi enfatizado, a Libras é uma língua natural do surdo, de modalidade visual-espacial, que possibilita a interação com os estímulos externos e a 
comunicação com outros sujeitos, fazendo com que ele se desenvolva cognitiva e socialmente, pois consegue se constituir como sujeito perante o mundo e seus significados. A família é a principal instituição que desenvolve a primeira forma de comunicação com a pessoa surda; assim, a forma de comunicação pessoal e familiar vai direcionar como será a formação subjetiva do sujeito surdo, direcionando os níveis de interação e desenvolvimento. Esse processo pode ser a primeira barreira do indivíduo surdo, porque, como relatam os Docentes I e J, os familiares, muitas vezes, não possuem conhecimento sobre a Libras, ou não há aceitação para sua utilização, o que impossibilita uma comunicação efetiva e saudável dessa família e dificulta a possibilidade de contribuição efetiva para educação da pessoa surda.

Schemberg, Guarinello e Massi (2012) reafirmam as falas anteriores, quando apontam que, em muitos casos, não há uma língua comum entre o sujeito surdo e sua família para permitir um contato social e a vivência nas interações. Estudos mostram que as famílias continuam a usar somente a língua oral e acabam não estruturando códigos linguísticos realmente eficazes para a interação com o sujeito surdo. Até pode haver o uso de "sinais familiares", mas eles configuram uma comunicação pobre, já que não possibilitam uma interação ampla com os sujeitos.

Assim, a família tem um papel de destaque para alicerçar a constituição do sujeito e seu desenvolvimento educacional; e a escola é incapaz de dar conta sozinha, principalmente do aluno surdo, sem o envolvimento da família. Para que haja uma educação libertadora e transformadora, é necessário o envolvimento de todos os atores nesse processo, a família, o aluno e o corpo escolar, por isso é importante que se estabeleça entre eles uma língua comum, para uma comunicação positiva, sendo a Libras o meio capaz de proporcionar esse movimento em todos os espaços da vida (SCHNEIDER, 2006).

No relato do Docente K, percebe-se um processo interessante da escola, o de oferecer o curso de Libras para as famílias dos alunos surdos; essa estratégia estreita o vínculo com a escola, além de proporcionar para o aluno um novo meio de interação com sua família, estruturada e possível de ser levada para todos os outros meios da vida, o que é impossível realizar com os "sinais familiares". Com a Libras como meio de comunicação, a constituição subjetiva do sujeito passará a aderir significados mais amplos e novas relações cognitivas, emocionais e sociais que talvez ele nunca tenha vivenciado.

Ainda sobre a questão da aceitação da família sobre a utilização da Libras como meio de comunicação, destacam-se os seguintes relatos:

No primeiro ano, foi muito difícil, mas agora os pais já perceberam que necessitam conhecer Libras para se comunicar melhor e de maneira correta com seu filho, para que, assim, o seu filho possa se desenvolver melhor (Docente L). 
A priori encontra-se resistência à Libras pela família do aluno surdo, talvez por desconhecimento ou por que já estabeleceram sinais familiares (Docente M).

As famílias que têm seus filhos na instituição desconhecem a importância da aprendizagem em Libras talvez pela sua própria cultura do oralismo. Há reconhecimento da instituição nesta aproximação, desfazendo alguns questionamentos contrários e organizando encontro de convivência, promovendo interações entre pais, fortalecendo os vínculos e desmistificando o aprendizado da Libras (Docente N).

Nos depoimentos, percebe-se que, em um primeiro momento, as famílias se mostram resistentes ao uso da Libras, acreditam que os "sinais familiares" são suficientes para a comunicação do surdo. Mas, com o passar do tempo, isso vai se modificando, e há aceitação e reconhecimento da Libras como meio fundamental para a interação e o desenvolvimento do sujeito surdo. Inicialmente, a família pode não reconhecer as implicações da surdez para o sujeito, com as particularidades, as possibilidades comunicativas e as dificuldades de inserção nos diversos contextos sociais, porém isso pode vir à tona quando o sujeito começa a transitar por outros espaços, como a escola. Assim, os familiares começam a reconhecer que existem essas barreiras e podem abrir para alternativas de comunicações mais efetivas para o sujeito surdo, como é o caso da Libras (SCHEMBERG; GUARINELLO; MASSI, 2012). As interações linguísticas no contexto familiar não são vistas como decisivas para a interação, pois possuem "sinais familiares" que, mesmo pobres, possibilitam certo grau de interação; somente nos meios externos essa necessidade é colocada como determinante para as interações, por isso há esse reconhecimento.

\section{Conclusão}

A escola e a família desempenham papel fundamental na constituição do sujeito surdo, assim, sua interação é imprescindível, pois essa pessoa está exposta constantemente a diversas barreiras, e essa interação pode contribuir para a sua superação e para o seu desenvolvimento. A educação é instrumento essencial para o sujeito enfrentar os desafios do mundo contemporâneo, por isso, é muito importante a contribuição de todas as pessoas que rodeiam os surdos.

É necessário entender que toda família é subjetiva e vivencia de maneiras diferentes o fato de ter um surdo como seu membro. Então, é importante que a instituição escolar leve isso em conta, além de, quando se deparar com famílias resistentes, que não lidam bem com a surdez, ser capaz de direcioná-las a serviços de apoio ou se colocar, ela mesma, como apoio para intermediar essas questões (DESSEN; POLONIA, 2007). Por isso, é fundamental que toda escola seja aberta à comunidade e que tenha espaços coletivos para discutir questões dessa natureza 
e para aproximar os vínculos com essas famílias em prol do desenvolvimento do aluno surdo.

No presente estudo, constatou-se que os fatores mais apontados pelos professores da rede pública de ensino de diferentes regiões brasileiras para a interação família-escola são a organização do ambiente educacional e a dificuldade de responsabilização e instrução dos familiares. Esses professores destacaram que as estratégias para propiciar e melhorar a interação família-escola estão na construção de novos arranjos organizacionais no ambiente escolar, como disponibilização de novos espaços de integração, cursos de formação, participação em apresentações, rodas de conversa e oferecimento de curso de Libras aos familiares de sujeitos surdos. Essas estratégias vão além do espaço da reunião administrativa escolar, que é tradicionalmente utilizada como a única ponte de comunicação com a família, ou seja, há a ampliação de novas formas de integração, que ultrapassam os espaços formalizados. Isso rompe a lógica que legitima a necessidade da família na escola apenas quando ocorrem dificuldades acentuadas no percurso escolar do aluno.

Outro fator que emergiu nas respostas foi a resistência das famílias ao uso da Libras, que exige do docente certo grau de capacidade para lidar com esses entraves ao processo pedagógico e interacional, de maneira que este precise lançar mão de novas táticas, a fim de gerar um movimento de informação e tomada de posição das famílias sobre a importância dessa língua para o desenvolvimento do surdo. Além disso, a escola precisa oferecer espaços para discutir essa questão e dar informações sólidas que legitimem a importância da realização de uma comunicação efetiva e completa com os surdos por intermédio da Libras.

A reflexão sobre a necessidade de professores com conhecimentos para lidar com as particularidades dos surdos e suas interações família-escola evidencia a importância da formação continuada de docentes e, assim, também, o curso de extensão em "Aperfeiçoamento em Atendimento Educacional Especializado para alunos surdos".

Os ganhos alcançados com a construção da parceria entre escola e família são diversos, como melhorar o grau de instrução da família sobre seus direitos, responsabilidades e recursos, que podem contribuir para o enfrentamento de barreiras, além de várias elucidações sobre questões que envolvem as particularidades das pessoas surdas, como cultura, comunidade, questões sociais e de luta. Ainda, essa parceria contribui para as famílias exercerem seu papel de agentes mediadores e colaboradores para potencializar os conhecimentos construídos no âmbito escolar (PEREZ, 2008). 


\section{Referências}

ALMEIDA, Maria José Freire. O desenvolvimento da literacia na criança surda: uma abordagem centrada na família para uma intervenção precoce. Revista Mediações, Portugal, v. 1, n. 1, p. $142-155,2009$.

BARBA, Patrícia Carla de Souza Della; MINATEL, Martha Morais. Contribuições da Terapia Ocupacional para a inclusão escolar de crianças com autismo. Cadernos de Terapia Ocupacional da UFSCar, São Carlos, v. 21, n. 3, p. 601-608, 2013.

CARNEIRO, M. A. LDB fácil: leitura crítico-compreensiva artigo a artigo. 9. ed. Petrópolis: Vozes, 2003.

CRESWELL, John W. Projeto de pesquisa: métodos qualitativo, quantitativo e misto. Trad. Magda Lopes. 3. ed. Porto alegre: Artmed, 2010.

DENZIN, N. K.; LINCOLN, Y. S. Introdução: a disciplina e a prática da pesquisa qualitativa. In: _. Planejamento da pesquisa qualitativa: teorias e abordagens. Porto Alegre: Artmed, 2006, p. 15-42.

DESSEN, M. A.; POLONIA, A, da C. A família e a escola como contextos de desenvolvimento humano. Paidéia, Ribeirão Preto, v. 17, n. 36, p. 21-32, 2007.

HOLLERWEGER, Silvana; CATARINA, Mirtes Bampi Santa. A importância da família na aprendizagem da criança especial. Revista Educação do Ideau, Erechim, v. 9, n. 19, p. 01-12, jan./jun. 2014.

KELMAN, Celeste Azulay et al. Surdez e família: facetas das relações parentais no cotidiano comunicativo bilíngue. Linhas Críticas, Brasília, v. 17, n. 33, p. 349-365, maio/ago. 2011.

LACERDA, Cristina Broglia Feitosa de. A inclusão escolar de alunos surdos: o que dizem alunos, professores e intérpretes sobre esta experiência. Cadernos Cedes, Campinas, v. 26, n. 69, p. 163184, maio/ago. 2006.

MARTINS, Sandra Veralúcia Marques; TAVARES, Helenice Maria. A família e a escola: desafios para a educação no mundo contemporâneo. Revista da Católica, Uberlândia, v. 2, n. 3, p. 256-263, 2010.

NEGRELLI, Maria Elizabeth Dumont; MARCON, Sonia Silva.Família e criança surda. Ciência, Cuidado e Saúde, Maringá, v. 5, n. 1, p. 98-107, jan./abr. 2006.

PEREZ, Márcia Cristina Argenti. Família-escola: discutindo finalidades, rupturas e desafios no processo educativo. In: CAPELLINI, V. L. M. F. (Org.). Práticas em educação especial e inclusiva na área da deficiência mental. Bauru: MEC/FC/SEE, 2008. p. 12-15.

SCHEMBERG, S.; GUARINELLO, A. C.; MASSI, G. O ponto de vista de pais e professores a respeito das interações linguísticas de crianças surdas. Revista Brasileira de Educação Especial, Marília, v. 18, n. 1, p. 17-32, jan./mar. 2012.

SCHNEIDER, R. Educação de surdos: inclusão no ensino regular. Passo Fundo: UPF Editora, 2006.

VIGOTSKI, L.S. A construção do pensamento e da linguagem. São Paulo: Martins Fontes, 2001. Fundamentos de defectologia. La Habana: Pueblo y Educación, 1989. 